\title{
Integral Test Facility PKL: Experimental PWR Accident Investigation
}

\author{
Klaus Umminger, Lars Dennhardt, Simon Schollenberger, and Bernhard Schoen
}

Technical Center, AREVA NP GmbH, Erlangen, Germany

Correspondence should be addressed to Klaus Umminger, klaus.umminger@areva.com

Received 15 August 2011; Accepted 16 November 2011

Academic Editor: Alessandro Del Nevo

Copyright ( $) 2012$ Klaus Umminger et al. This is an open access article distributed under the Creative Commons Attribution License, which permits unrestricted use, distribution, and reproduction in any medium, provided the original work is properly cited.

\begin{abstract}
Investigations of the thermal-hydraulic behavior of pressurized water reactors under accident conditions have been carried out in the PKL test facility at AREVA NP in Erlangen, Germany for many years. The PKL facility models the entire primary side and significant parts of the secondary side of a pressurized water reactor (PWR) at a height scale of $1: 1$. Volumes, power ratings and mass flows are scaled with a ratio of $1: 145$. The experimental facility consists of 4 primary loops with circulation pumps and steam generators (SGs) arranged symmetrically around the reactor pressure vessel (RPV). The investigations carried out encompass a very broad spectrum from accident scenario simulations with large, medium, and small breaks, over the investigation of shutdown procedures after a wide variety of accidents, to the systematic investigation of complex thermal-hydraulic phenomena. This paper presents a survey of test objectives and programs carried out to date. It also describes the test facility in its present state. Some important results obtained over the years with focus on investigations carried out since the beginning of the international cooperation are exemplarily discussed.
\end{abstract}

\section{Introduction}

Complex thermal-hydraulic system codes are used for the analysis of accident sequences in pressurized water reactors. The necessity to verify the knowledge gained using such codes by experiments in suitable test facilities resulted in the construction of the large-scale test facility PKL (from the German abbreviation for Primärkreislauf) modeling a 1300 MW class PWR.

The PKL test facility has been in operation since 1977; however, in the meantime, the objectives of the experiments performed at the PKL test facility have changed considerably with the result that the test rig has been refitted many times to suit the additional and ongoing tasks and also to match latest developments, for example, in the fields of measuring instrumentation and data processing. Since the commencement of experiments at the PKL test facility, the various phases of the experiments have always reflected and given priority to current safety issues.

The primary objective of all PKL experiments has been and remains the experimental investigation of thermalhydraulic processes in PWRs with respect to the response of the overall system. To some extent the investigations also include the behavior of individual components and subsystems during the simulation of operational transients and accidents. The tests performed to date (in total more than 150 integral experiments) have altogether contributed to a better understanding of the sometimes highly complex thermal-hydraulic processes involved in various accident scenarios and to a better assessment of the countermeasures implemented for accident control. In addition, they have supplied valuable information regarding safety margins available in the plants. The test results have also found concrete application in the validation and further development of thermal hydraulic computer codes, the so-called system codes.

\section{PKL Test Programs}

Reactor safety research in the seventies centered above all on the theoretical and experimental analysis of large-break loss-of-coolant accidents (LOCAs), focusing on verifying the effectiveness of the emergency core cooling system 


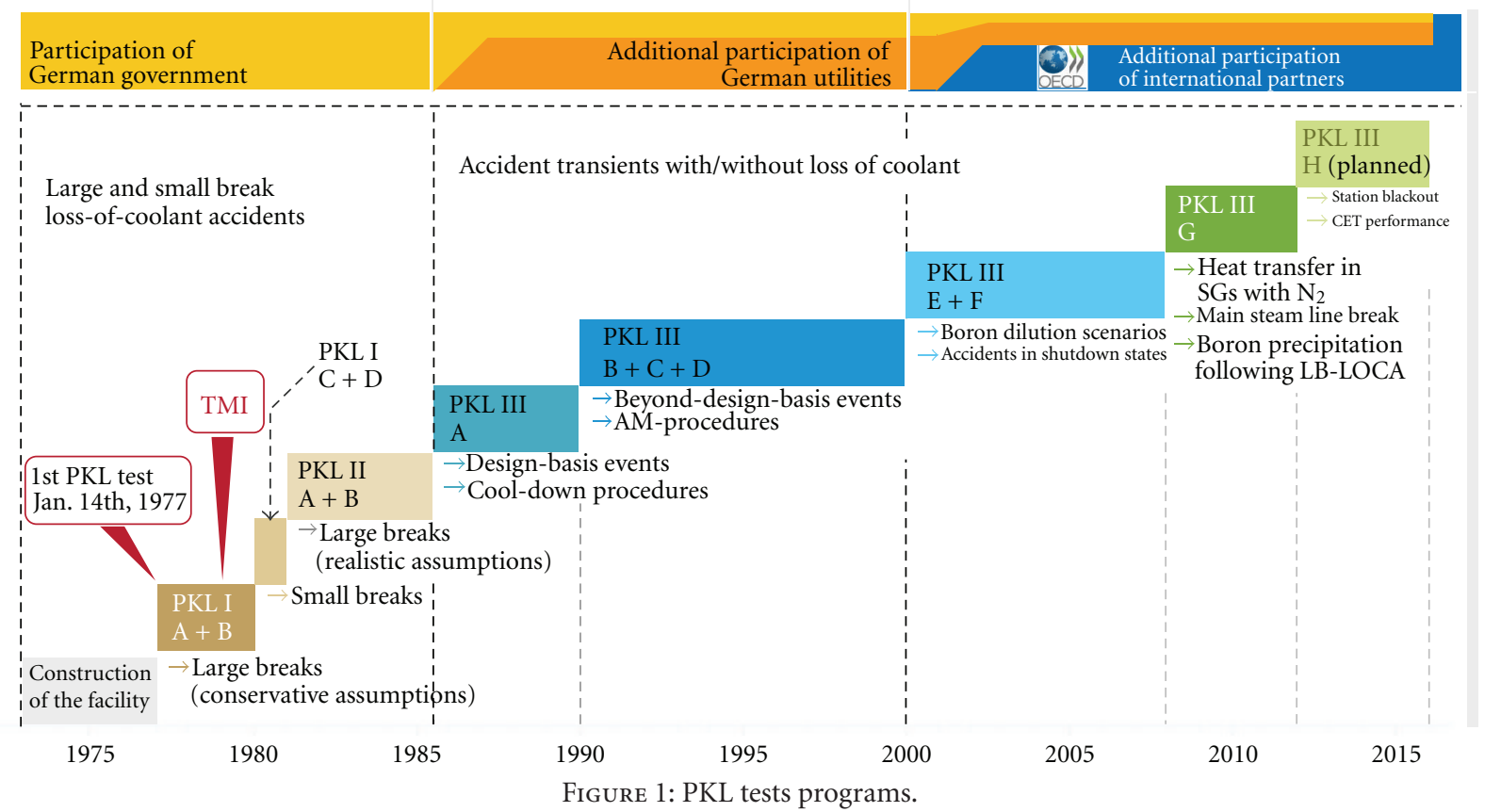

(ECCS) required for controlling such events. Based on this original objective, the PKL test facility was constructed at Siemens/KWU (now AREVA NP) with the support of the German Ministry for Research and Technology and placed in service in 1977 (Figure 1).

The large-break LOCA experiments were interrupted in 1979 in the wake of the accident at three-mile island unit 2 (TMI-2) for the performance of experiments at the PKL test facility designed to contribute to gaining information as quickly as possible on issues raised by this event. Consequently, only a short time after the accident, it was possible to simulate small-break (SB) LOCA event sequences, which also included the TMI-2 scenario, at the PKL test facility. The investigations focused on demonstrating the safety margins of the operating units through the experimental verification of the effectiveness of the engineered safety features in the event of large- and small-break LOCAs were covered within the test programs PKL I and II $[1,2]$.

The subject of the subsequent PKL III program, started in 1986, has been the investigation of the so-called accident transients with and without LOCAs. While the first test series within PKL III covered design-basis accidents and cooldown procedures detailed in the operating manual, the main interest was then focused on beyond-design-basis accidents and the experimental verification of accident-management procedures [3]. Typical topics of investigation studied within the test series PKL III A to PKL III D were

(i) cool-down procedures with and without reactor coolant pumps under symmetric and asymmetric boundary conditions (e.g., one or more SGs isolated on the secondary);

(ii) cool-down procedures following small-break LOCAs or steam generator (SG) tube ruptures, partly in combination with additional system failures; (iii) accident management procedures (e.g., secondary or primary side bleed-and-feed) following total loss of feed water or multiple failure situations;

(iv) systematic investigations within parametric studies such as

(1) single- and two-phase flow, reflux condensation, counter current flow limitation,

(2) influence of noncondensable gas on heat removal from the primary to the secondary.

Since 2001, the PKL project has been continued in the course of an international project initiated by the OECD. The major topics covered by the experiments between 2001 and 2007 were

(i) boron dilution events following SB-LOCA,

(ii) loss of residual heat removal under shut-down conditions.

The current test program PKL III G which will last until end of 2011, additionally addresses the following main topics.

(i) Subcooling transients after a break in the main steam line (with supplementary tests in the ROCOM test facility for mixing in the RPV downcomer and in the lower plenum).

(ii) Cool-down procedures with SGs isolated and emptied on the secondary side.

(iii) Boron enrichment and precipitation in the core after primary-side large-break accidents.

(iv) Systematic investigations of the heat transfer in the SGs in the presence of noncondensable gas (with complementary tests in the Hungarian PMK test facility for horizontal SGs). 


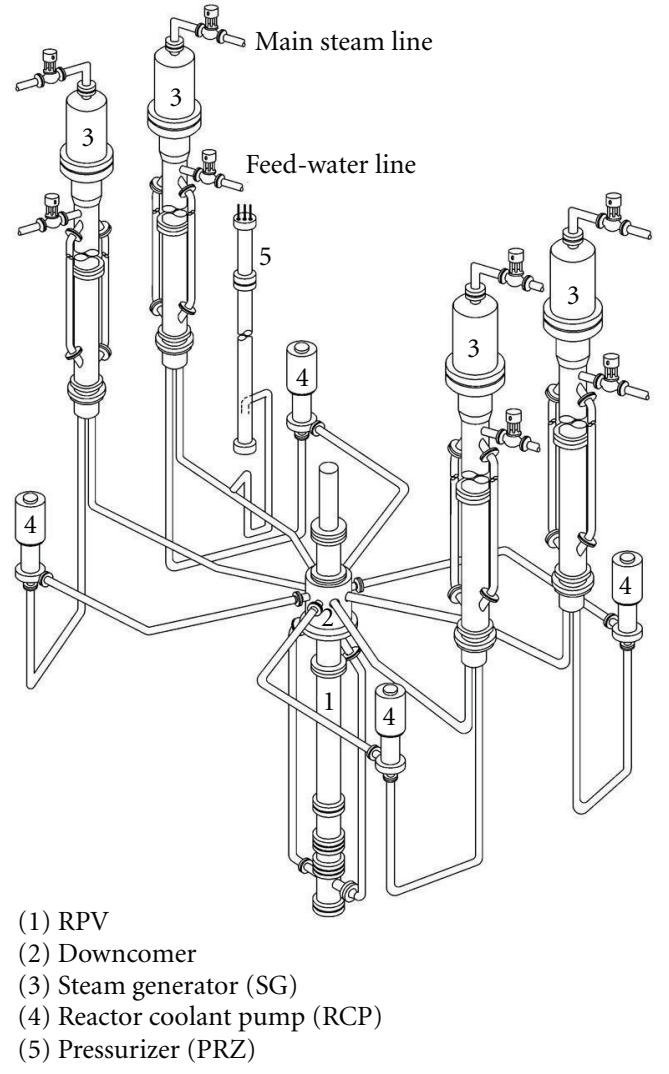

FIgURE 2: PKL test facility.

(v) Systematic study on heat transfer in the SG under reflux condenser conditions (influence of secondary side parameters).

(vi) Small break LOCA with failure of safety injection pumps and secondary-side depressurization as accident management measure (counterpart test with ROSA/LSTF).

(vii) Formation of RPV upper head void during cooldown under natural circulation (NC) conditions in emergency power mode.

\section{Description of the Test Facility}

The layout of the PKL-III facility (Figure 2, Table 1) is based on the "Vorkonvoi" type (4-Loop, 1300 MWe) of KWU pressurized water reactor, with the Philippsburg 2 nuclear power plant serving as the reference plant. The entire primary side and the most significant components of the secondary side (excluding turbines and condenser), including the appropriate system technology, are represented. Because the essential construction principles of the western types of PWRs are similar, it is possible to make statements concerning the behavior of other companies' plants. In any case, the analysis of plant-specific reactor transients must then be made with the help of computer codes.

Following the scaling concept, all geodetic heights are represented in a 1:1 ratio. The entire volume of the primary side and, as far as possible, the partition of the individual
TABLE 1: Scaling and operating parameters.

\begin{tabular}{lc}
\hline Elevations & $1: 1$ \\
Volumes & $1: 145$ \\
Max. core power & $2.5 \mathrm{MW} \rightarrow 10 \%$ \\
Max. pressures & \\
$\quad$ Primary & $45 \mathrm{bar}$ \\
$\quad$ Secondary & $60 \mathrm{bar}$ \\
Flow rates & $35 \mathrm{~kg} / \mathrm{s}(\mathrm{RCPs}$ operating $)$ \\
Temperatures & \\
$\quad$ Primary fluid & $300^{\circ} \mathrm{C}$ \\
$\quad$ Sec. fluid & $300^{\circ} \mathrm{C}$ \\
$\quad$ Max. rod cladding & $750^{\circ} \mathrm{C}$ \\
\hline
\end{tabular}

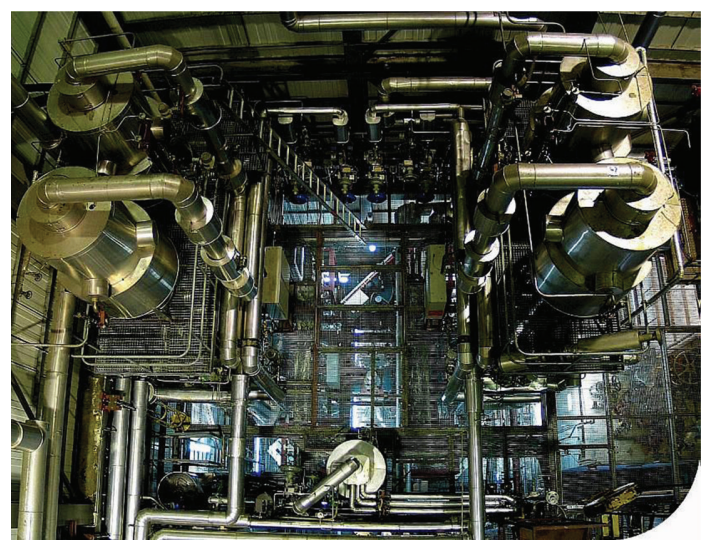

Figure 3: PKL steam generators (top view).

volumes corresponds to a scaling factor of $1: 145$, which corresponds to a hydraulic diameter reduction of $1: 12$. For some components, the exact volume scaling was not applied in order to simulate certain thermal-hydraulic phenomena, for example, countercurrent flow limitation in the hot legs. This allowed dimensionless numbers (e.g., the Froud number) to be maintained in the correct parameter range. The single-phase pressure losses, correspond to a large extent to the values in a PWR. Together with the thermal losses they have been determined in detail for every component and section for the entire load and temperature ranges (reactor coolant pump (RCP) operation and NC conditions under cold and hot conditions).

The core is modeled by a bundle of 314 electrically heated rods with a total power of $2.5 \mathrm{MW}$ corresponding to $10 \%$ of the scaled nominal power. The core geometry is, like the SG geometry, constructed as an "actual section"; that is, the individual heated rods and U-tubes have the actual geometry, but the number of heated rods in the core and the number of U-tubes in the SG are reduced by the scaling factor $1: 145$, (volume and power scaling) as compared to the original plant. The PKL heater rod bundle has a uniform axial power profile, and the heater rods are arranged in three concentric zones (heated independently of one other) which enables radial power profiles across the test bundle to be simulated. The four fully scaled SGs (see top view in Figure 3 ) are 


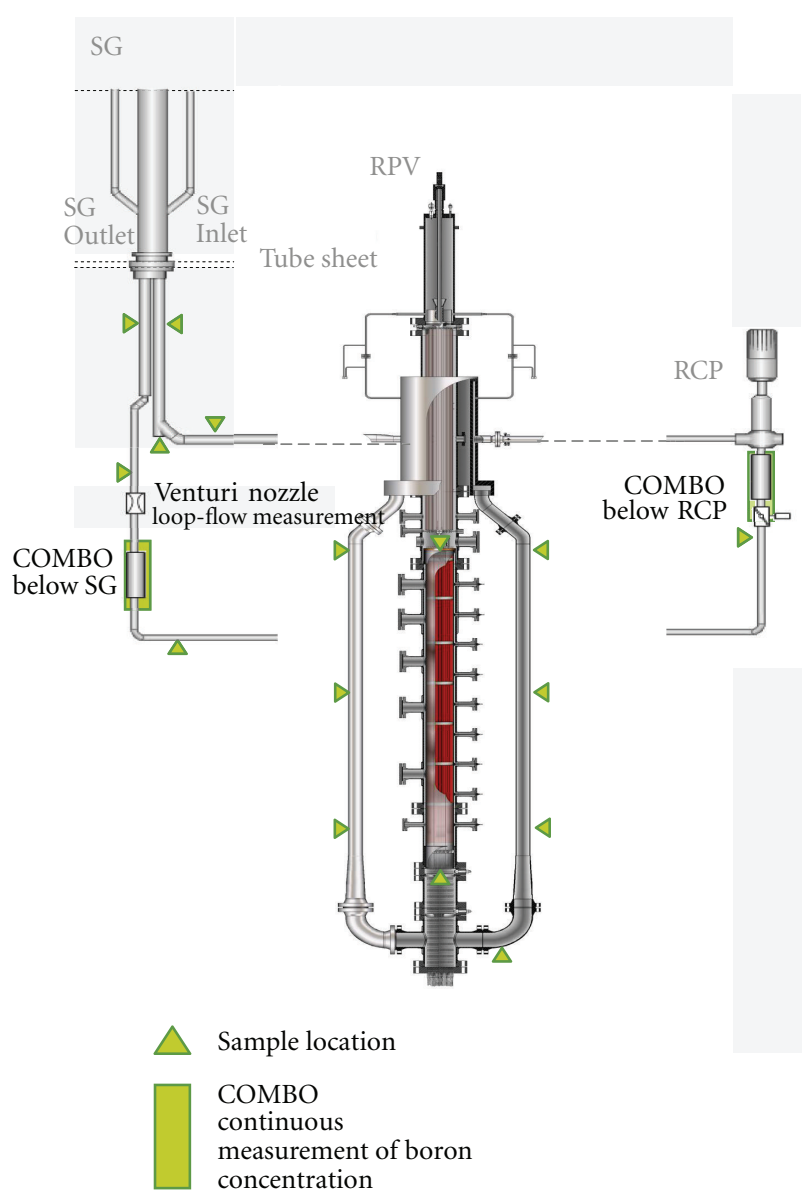

FIGURE 4: Boron concentration and loop-flow measurements.

equipped with prototypical tubing (diameter, wall thickness, differing lengths) and tube sheet. The RPV downcomer is modeled as an annulus in the upper region and continues as two stand pipes connected to the lower plenum. This configuration permits a symmetrical connection of the 4 cold legs to the RPV, reliable determination of flow rates, preserves the frictional pressure losses, and does not unacceptably distort the volume/surface ratio. This is of importance with respect of the removal of stored heat from the walls during cool down. In general, the structure masses resulting from the limitation of pressure to 45 bar return the relation between heat capacities of structures and coolant masses to be in good accordance with the reference plant.

The symmetrical arrangement of the 4 loops around the RPV also allows investigating the individual effects of multiple system failures.

Experiments on the behavior of a 3-loop (2-loop) plant can also be conducted by simply isolating one (two) loop(s). Each of the primary side loops contains active RCPs, which are equipped with speed controllers to enable any pump characteristics to be simulated. Preserving the frictional pressure losses in the SGs and in the core region, the integral pressure loss for the entire primary system is also very similar to that of the actual plant.
PKL is also equipped with all relevant engineered safety and operational systems on the primary and secondary side. On the primary side, four independent high- and low-pressure safety injection systems connected to both, the hot and cold legs, the residual heat removal system, 8 accumulators, the pressurizer pressure control system, and the chemical and volume control system are simulated. On the secondary side the feed, water system, the emergency feed water system and the main steam lines with all control features of the original systems are modeled. For the realistic representation of the events in secondary-side bleed-andfeed operations, the complex geometry of the feed water system (all heights $1: 1$, volumes $1: 145$, pressure losses $1: 1$ ) was modeled with the possibility of setting the corresponding temperature distributions. All these features allow the simulation of a wide spectrum of accident scenarios, the interaction between the primary and secondary side in combination with various safety and operational systems.

The maximum operating pressure of the PKL facility is 45 bar on the primary side and 60 bar on the secondary side. This allows the simulation over a wide temperature range. However, certain constraints are placed on the application of insights gained from the test results to a PWR plant because of the primary pressure limit and because of the geometric scaling of the test facility. With respect to limitation of primary pressure, the scaling of the experiments is subject to three categories.

The first category of experiments provides results on special physical phenomena such as countercurrent flow limitation or the influence of nitrogen on accidents from cold shut-down conditions that are expected to occur at pressures below 50 bar.

Other experiments "enter" a PWR transient at a pressure level of 45 bar. The conditions at the start of testing are set up by the use of code calculation for the PWR, an example being SB-LOCAs where the important phenomena occur at pressures below 50 bar.

The third category covers scenarios where phenomena occurring at high pressures can be simulated at pressures below 50 bar with the results being extrapolated to the original pressures with the help of codes or by comparison with results from full-pressure test facilities. A typical example for the latter is the initial phase of bleed-and-feed experiments.

A scaling study [4] showed that the thermohydraulic properties and certain phenomena (density, single- and twophase heat transfer) do not change significantly between 40 and $80 \mathrm{bar}$. So most of the phenomena observed for pressures under 50 bar are in the first step qualitatively applicable to full scale PWR. In a second step, a quantitative application of experimental results to full-scale PWRs is always achieved by the use of further analyses with thermohydraulic codes. To what extent the test results from other test facilities (e.g., LSTF and BETHSY, pressure $1: 1$, or UPTF, geometry $1: 1$ ) $[5,6]$ or results from computer programs (e.g., ATHLET, CATHARE or RELAP) must be included is considered for individual cases.

With approximately 1500 measurement points (see Table 2), the PKL facility is comprehensively instrumented. 


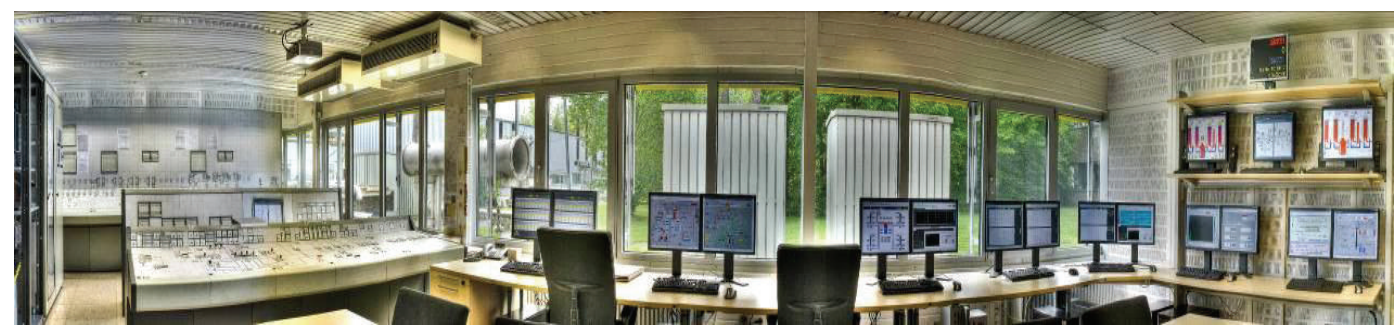

FIGURE 5: PKL-control room.

TABLE 2: Measurement installation in PKL III (selection).

\begin{tabular}{lcccccc}
\hline & RPV & SG & Loops & $\begin{array}{c}\text { Interfacing } \\
\text { systems }\end{array}$ & PRZ & Total \\
\hline Mass flow & 1 & & 14 & 64 & & 79 \\
Differential pressure & 9 & 18 & 20 & 8 & 3 & 58 \\
Fill level & 12 & 48 & 40 & 47 & 5 & 152 \\
Mass & & & & 3 & & 3 \\
Density & 10 & 2 & & 2 & 9 & 23 \\
Absolute pressure & 7 & 7 & 8 & 44 & 2 & 68 \\
Temperature & 286 & 345 & 182 & 158 & 29 & 1000 \\
Boron concentration & 16 & 4 & 32 & & 1 & 53 \\
Power measurement & 5 & 4 & 6 & 5 & 2 & 22 \\
Valve position [\%] & & & & 68 & & 68 \\
\hline$\sum$ & & & & & $\mathbf{1 5 2 6}$ \\
\hline
\end{tabular}

This allows detailed analysis and interpretation of the phenomena that develop in the course of the tests. Besides conventional measurements (temperature, pressure, etc.), two-phase flow measurements are also used. In addition, special measurement devices for the detection of boron concentration have been installed. Figure 4 exemplarily depicts the loop mass flows and boron concentration measurement locations.

All measurement data are recorded by a data acquisition system with a maximum sampling rate of $25 \mathrm{~Hz}$. In addition, all measurement signals can also be displayed and observed online during the test in the PKL control room. This includes the use of process visualization systems (Figure 5).

With regard to system technology and system design layout, the test facility is constantly being modified and expanded according to new project definitions and investigational emphases, and the applied measurement techniques are continually being updated to the state-of-the-art technology.

\section{PKL Test Results}

The number of integral experiments performed at the PKL test facility now totals more than 150. Consequently, only a representative sample of the test results and knowledge derived from them can be presented in summary for the various main areas of focus.

4.1. Large-Break LOCA. The hypothetical accident involving a large break in the reactor coolant system (RCS) piping (up

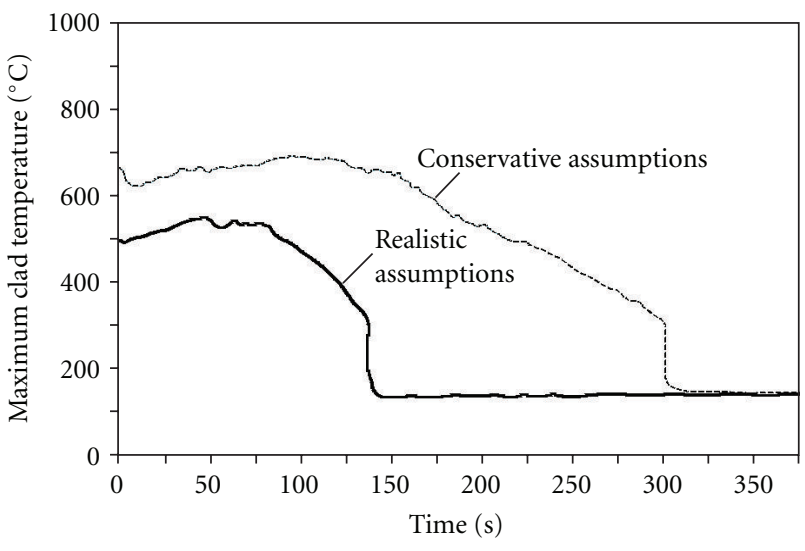

FIgURE 6: PKL test results for large-break LOCA.

to and including a complete guillotine break of a coolant line) is characterized by a large mass flow at the break and therefore by a rapid depressurization and loss of fluid from the RCS. The loss of cooling subsequently causes the clad temperatures to rise at first. In the so-called reflood and refill experiments which started from initial conditions with the system depressurized and the core heated up and with initiation of low-pressure safety injection, it was possible to obtain empirical verification of the ECCS concepts. In so doing, it was demonstrated that the restoration of core cooling is assured even with degraded operability of the ECCS (conservative assumptions). Further experiments which included the end of blowdown phase and which were performed under more realistic conditions, in particular as regards the operability of the ECCS and consideration of injection of the accumulator inventory, yielded even better results in relation to possible core degradation (lower clad temperatures and shorter time at elevated temperatures [1]). Figure 6 contrasts the results of two experiments performed under such conservative and realistic conditions.

4.2. Small-Break LOCA. Accidents involving small breaks in the RCS piping are characterized by the fact that a second energy sink such as the SG secondary side is needed for decay heat removal in addition to that provided by leakage makeup by the safety injection systems. First fundamental studies relating to small-break LOCAs performed shortly after the TMI-2 accident demonstrated that decay heat removal in PWRs with U-tube steam generators is assured even with a greatly reduced coolant inventory as long as the coolant level 

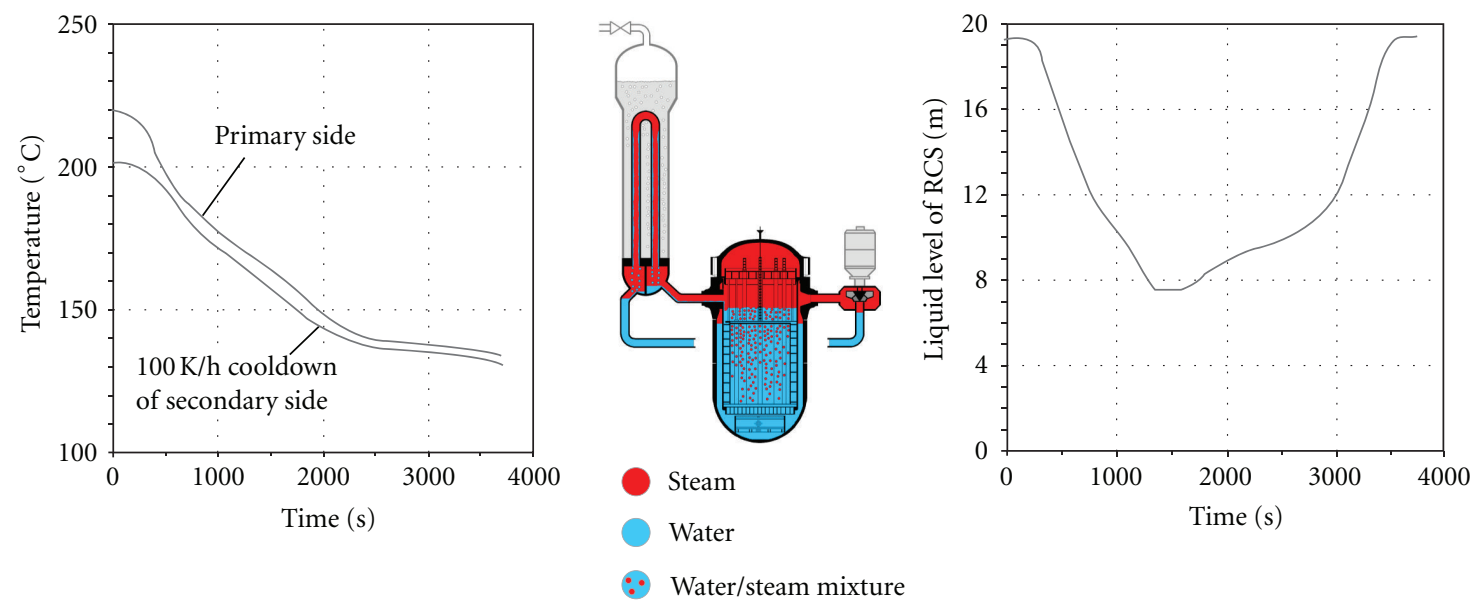

Small break in cold leg (0,02A), 2 safety injection pumps in cold leg

FIGURE 7: PKL test results for small-break LOCA.

in the reactor pressure vessel is at least as high as the top of the core. In this case, natural circulation breaks down and heat transport is provided by steam flow from the core to the SGs where the steam condenses and flows back to the core (reflux condenser mode). Furthermore, empirical verification was obtained that automatic plant cooldown is an effective means of quickly bringing the unit to a safe condition [2]. A typical result of a small-break LOCA experiment ( 2 of 4 high pressure safety injection pumps assumed operable) is shown in Figure 7 by the time histories for RCS and secondary-side pressure with the plant in the reflux condenser mode. In this case, the core is always filled with water or a water/steam mixture so that decay heat removal is assured at all times.

More extensive studies on small-break LOCA were performed in the course of the PKL III program considering additional failures and system malfunctions (e.g., loss of SGs as an energy sink, degraded heat transfer in the SGs due to the accumulation of inert gas in the SG tubes, reduced operability of the ECCS as far as the highly improbable situation of loss of all safety injection pumps, and simultaneous loss of automatic cool down). These showed that, even under these extreme conditions, it is possible to bring the plant safely to residual heat removal entry conditions by cooldown implementing the procedures prescribed in the operating manual or through beyonddesign-basis accident management measures initiated by the operator. They, therefore, demonstrated the enormous safety reserves of PWR units. Investigation addressing boron dilution events during SB-LOCAs has been performed within the test program PKL III E and F (see below).

4.3. Cool-Down Procedures after Non-LOCA Events. In particular, cool-down procedures $(50 \mathrm{~K} / \mathrm{h})$ were conducted with and without RCPs, in each case not combined with LOCA events, in order to confirm the operating manual procedures. Proceeding from a baseline test which modeled operational cooldown with 2 RCPs and 4 SGs, further tests were performed in which restricted operability of the circulation pumps (e.g., only one RCP) and emergency power conditions (no RCPs operable) and only partial operability of the SGs (e.g., only 3 or 1 SG operable for $50 \mathrm{~K} / \mathrm{h}$ cool down) were assumed. Across the board, the test results confirmed the feasibility of the procedures prescribed in the operating manual to achieve a safe, depressurized condition with decay heat removal by the residual heat removal system [7]. The formation of steam bubbles in the RCS (e.g., in the RPV closure head) does not degrade the prescribed cooldown procedures.

Contrary to the original assumption that the closure head bubble could extend into the reactor coolant piping and give rise to violent condensation mechanisms due to contact with subcooled water, the maximum extent of the closure head bubble always remains restricted to an area significantly above the reactor coolant piping, even under natural circulation conditions.

On restarting of the RCPs after auxiliary power recovery (offsite power supply operable), condensation and mixing processes in the presence of a steam bubble in the RPV closure head are so slow that abrupt and undesired level changes do not occur in the pressurizer, and continued controlled cool down remains assured.

The formation of a closure head bubble during cool down under emergency power conditions and condensation on restarting of the RCPs are shown by way of example in Figure 8. A further test recently performed (within the current test program PKL III G) on the formation and expansion of the upper head steam bubble under natural circulation conditions-applying however a different cool down procedure-confirmed these results and the dominating phenomena.

4.4. Beyond-Design-Basis Accident Management Measures. Emergency procedures have been devised to avert core melt processes in the event of beyond-design-basis events such 


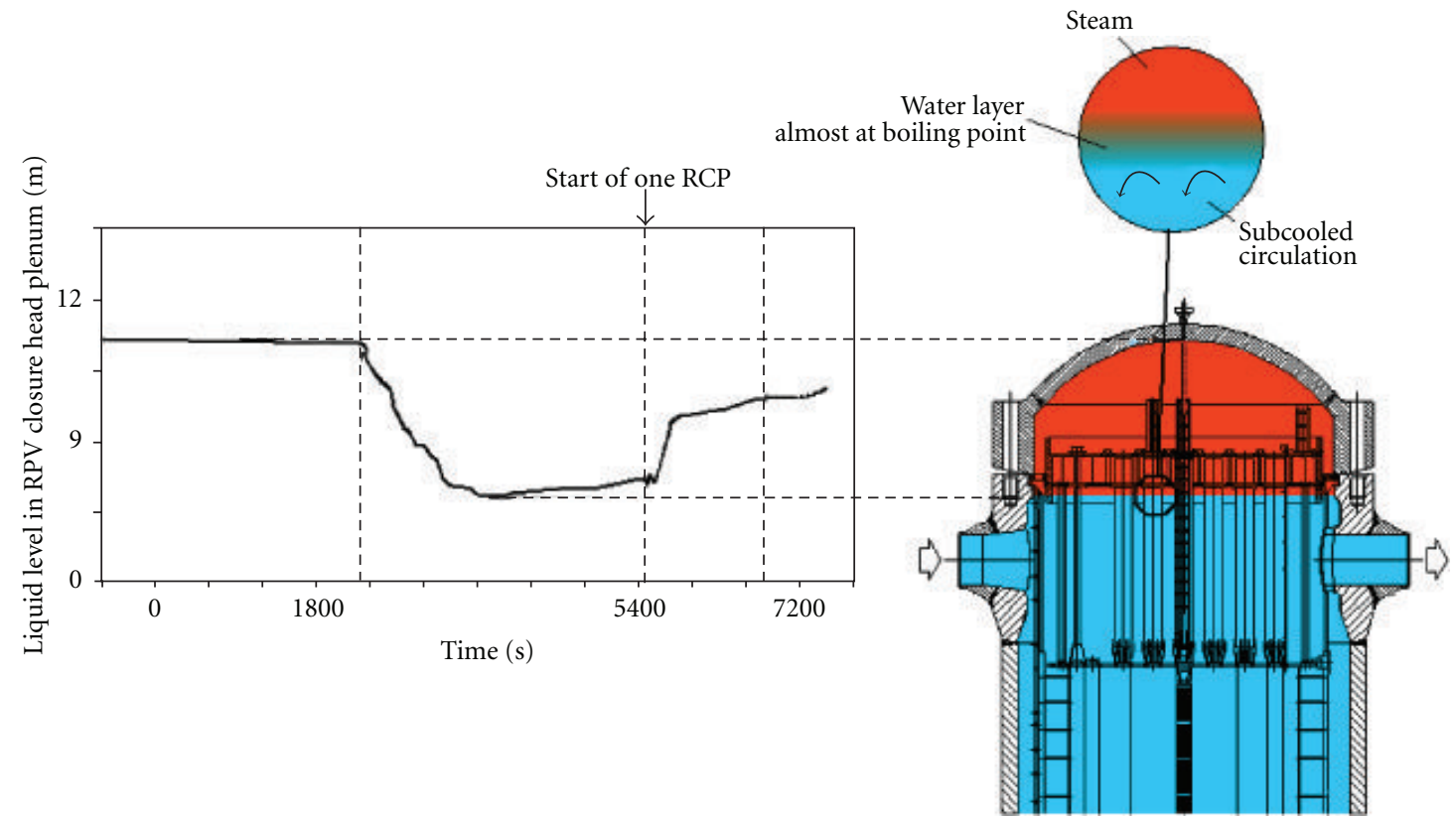

FIGURE 8: PKL III-Cooldown in emergency power mode with restarting of one RCP.

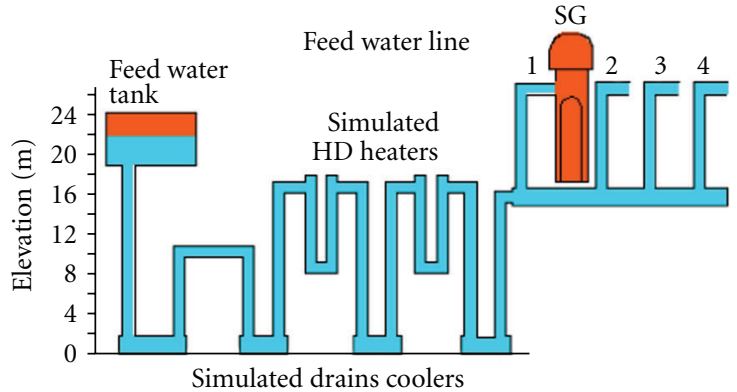

Steam

Water

(a) Before secondary-side bleed

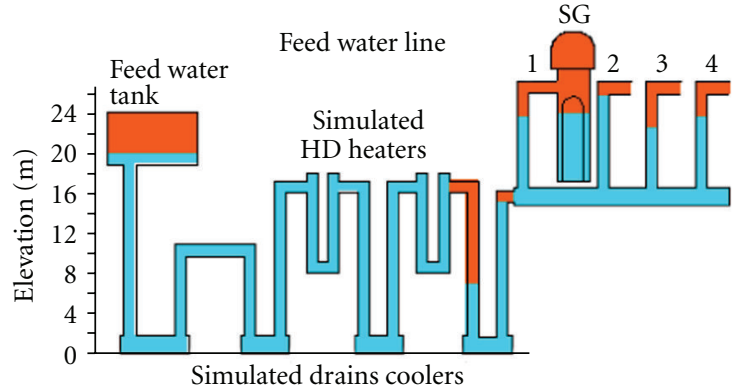

Steam

Water

(b) After "passive" steam generator feed

FIGURE 9: Test results for secondary-side bleed and feed.

as complete loss of feed water supply (loss of secondaryside heat sink), station blackout (additional loss of all ECCS on the primary side), or even multiple failure situations (e.g., small-break LOCA or steam generator tube rupture combined with additional system failures). The investigation of emergency procedures such as primary-side or secondaryside bleed and feed was one of the focal points of the PKL III (A-D) program of experiments. For example, a series of experiments was conducted for the systematic investigation of the effectiveness of secondary-side bleed and feed on loss of feed water supply (loss of all feed water pumps incl. emergency feed water pumps) and on station blackout by variation of system conditions and the time of initiation of bleed [8].

All the experiments on secondary-side bleed and feed clearly confirmed the effectiveness of this emergency procedure. The pressure reduction on the secondary side induces a passive injection of water from the feed water piping as a result of steam flashing and hence a rapid, temporary restoration of primary-to-secondary heat removal. Passive injection from the feed water piping and subsequent injection from the charged feed water tank can provide secondary-side heat removal for several hours with the result that sufficient time is available to secure heat removal from external water sources (e.g., mobile pumps), should the loss of normal and emergency feed water pumps persist so long as to require such measures to be taken. The inventory present in the feed water piping system and in the SGs prior to the initiation of secondary-side bleed and after emptying the feed water tank is schematically shown by way of example in Figure 9.

4.5. Boron Dilution Following SB-LOCA. In the course of a SB-LOCA in a PWR, the flow regime in the RCS passes through a number of different phases and the filling level may decrease down to the point where the decay heat is 


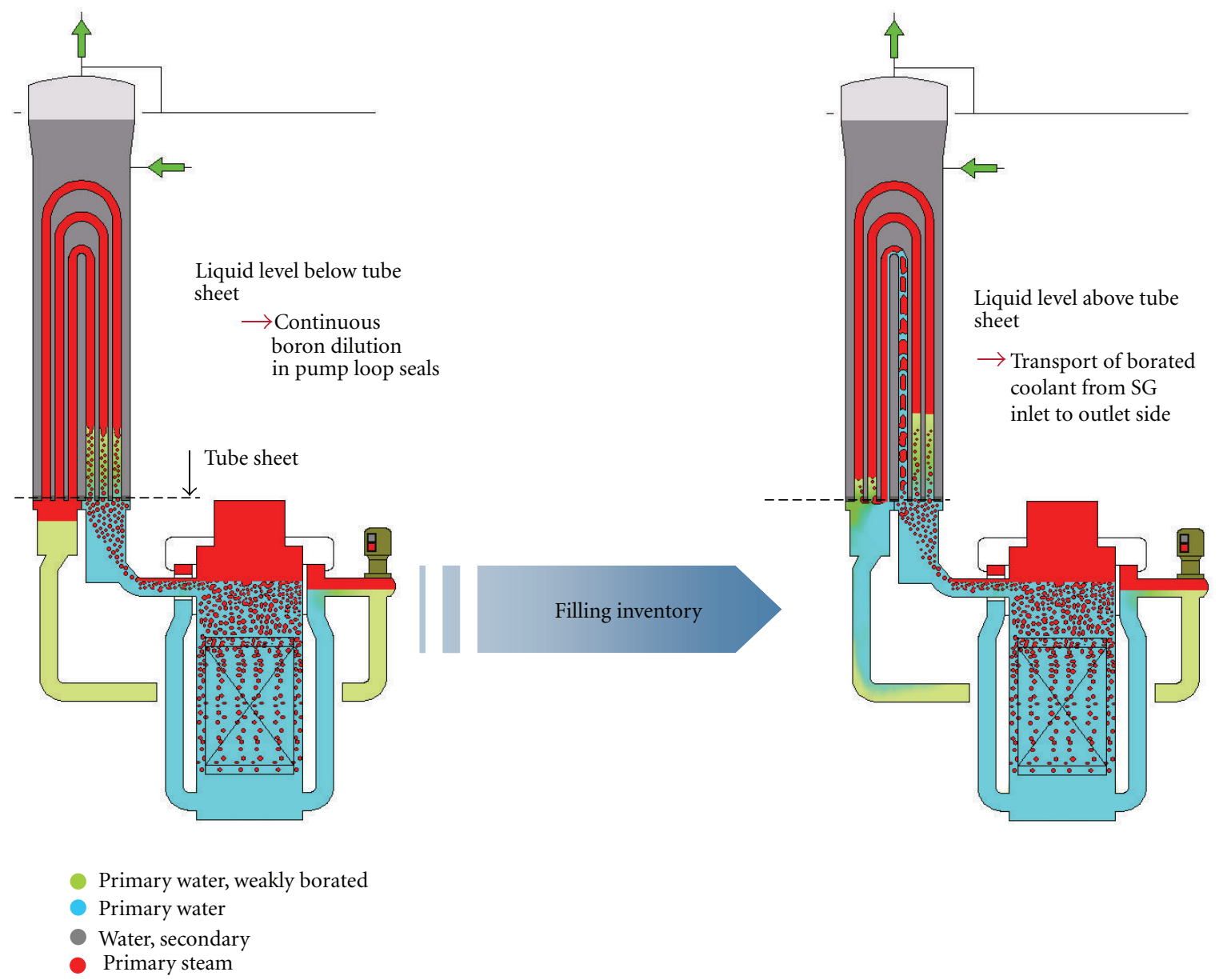

FIGURE 10: Initiation of RC operation and coolant transport dependent upon liquid level in SG outlet chamber.

transferred to the secondary side under reflux-condenser (RC) conditions (see Section 4.2). During RC, the steam formed in the core condensates in the SG U-tubes. For a limited range of break size and configuration, a continuous accumulation of condensate may cause the formation of boron-depleted slugs. If natural circulation reestablishes, as the RCS is refilled, boron-depleted slugs might be transported to the RPV and to the core raising the question if this could results in a local recriticality in the reactor core.

To draw conclusions on the risk of boron dilution processes in SB-LOCA transients in connection with recriticality, two important issues, the limitation of slug size and the onset of NC, have to be assessed on the basis of experimental data, as system thermal-hydraulic codes are limited in their capability to replicate the complex physical phenomena involved.

With regards to boron dilution, several integral and separate effect tests were conducted in the PKL test facility addressing the following issues:

(i) size of the "condensate slugs" that develop;

(ii) mixing in the SGs and during slug transport through loops with more highly borated water;

(iii) flow rate of the natural circulation onset transient; (iv) difference in time between the start of natural circulation in the different loops.

All the PKL boron dilution tests were performed with actual boric acid and with adequate measurement technology (continuous online measurement and probe samples) for determining boron concentration.

Main objective of the separate effect tests was to investigate systematically the inherent boron dilution processes due to RC conditions as a function of the primary coolant inventory at a constant primary pressure (Figure 10). Within parametric studies under quasisteady state conditions, the primary side inventory was stepwise reduced and increased notably in order to investigate the behavior of the boron concentration at the SG outlet in the transition regime between 2-phase NC and RC conditions, which is passed through when the system is voided and, as well, when it is refilled. In that way, the onset of a boron dilution process during the voiding phase and the stopping of the boron dilution process during the refilling phase as function of the primary side inventory could be determined. The individual tests vary by different primary pressures (12 to 40 bar).

Major objective of the integral tests was to investigate the transient behavior, that is, the time history of SBLOCA with inherent boron dilution under certain boundary 


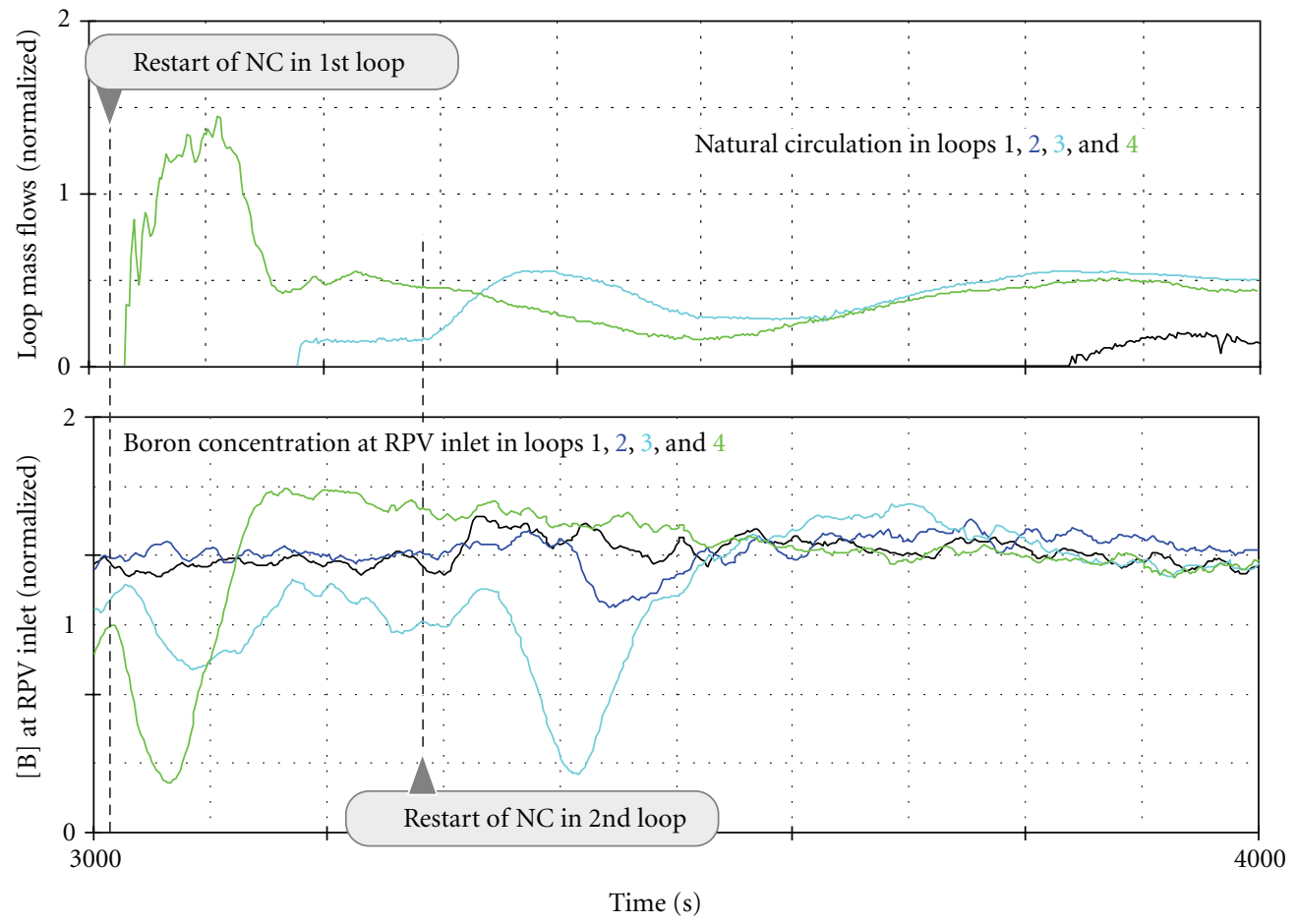

FIgURE 11: Loop mass flow rate and boron concentration.

conditions (e.g., different ECC injection configurations and cool-down rates). The results for natural circulation in the individual loops and for the conditions in the weakly borated slugs obtained from PKL tests serve as boundary conditions for complementary investigations on mixing in the RPV downcomer annulus and in the lower plenum (e.g., CFD analysis or mixing experiments in the ROCOM and JULIETTE test facilities).

Due to the pressure limitation, it is not possible to simulate the high-pressure portion of accident sequences (such as small-break LOCAs) starting from a PWR's actual operating pressure (155-160 bar) under original conditions. Hence, the OECD PKL tests "start" at a primary system pressure of 45 bar and with initial conditions corresponding to those that would prevail in a real plant at this time (i.e., when the primary system pressure is at this level). These initial conditions are obtained from analyses conducted using system codes (such as RELAP 5 or CATHARE) for a real PWR geometry and corresponding boundary conditions and are realized within the so-called conditioning phase.

The remainder of the accident sequence, where the most relevant phenomena are expected to occur (e.g., for the small break LOCA tests described here: refilling, onset of natural circulation, and transport of low-boron water in the direction of the RPV) is then simulated in the tests using real PWR pressures.

The findings for small-break accidents may be summarized as follows.

(i) For a large and long-lasting loss of coolant, weakly borated condensate slugs can build-up in the crossover leg. However, the buildup of weakly borated condensate in the crossover leg can only occur when the primary side liquid level in the outlet side of the SGs lies below the tube sheet (Figure 10). At higher water levels, transport processes of highly borated water from the inlet to the outlet side in some U-tubes prevent the further accumulation of condensate. As a consequence, the maximum slug size is limited to the volume of the crossover leg plus the volume of the SG outlet plenum.

(ii) The NC does neither start simultaneously in all loops nor isochronously in the U-tubes of a single SG. As circulation starts in one loop, the impetus is reduced for circulation to start in other loops. As a consequence weakly borated condensate from individual loops does not reach the RPV at the same time (Figure 11), a fact that reduces the risk of recriticality.

(iii) In the refill process, effective mixing processes are present in the SGs and the loops before onset of natural circulation due to overspilling of borated water from the inlet to the outlet side of the SGs (partial disintegration of the boron-depleted slugs).

The OECD PKL tests on boron dilution greatly improved the knowledge of the transient and of the complex physical phenomena involved. With these PKL tests and the derived findings as a substantial element, the final assessment against boron dilution for specific plant designs is finally to be done in conjunction with thermohydraulic system codes (system behavior), investigations on mixing in the RPV downcomer 
and lower plenum (CFD or mixing experiments) and neutronics analysis (consequences on core) [9].

4.6. Loss of Residual Heat Removal during Mid-Loop Operation. When a PWR is shut down for refueling, the main coolant inventory is reduced so that the level is at midloop elevation. For spatial replacement of water, nitrogen is injected into the primary. At the so-called mid-loop operation, removal of the decay heat from the core is maintained by the residual heat removal system (RHRS), which under these conditions represents the heat sink. Loss of RHRS under shut down conditions has occurred several times worldwide and still plays an important role in risk studies for PWRs. As long as the primary circuit is closed, a failure of the residual heat removal system can be compensated by one or more SGs, which remain filled with water on the secondary side and stay ready for use during refueling and other outages.

With regards to loss of RHRS with closed RCS, several integral and separate effect tests were conducted in the PKL test facility [10]. These tests also performed with actual boric acid and adequate measurement techniques for boron concentration were focusing on the following issues:

(i) heat transfer in the SG(s) in presence of nitrogen,

(ii) stabilization of primary pressure,

(iii) possible boron dilution processes.

If a long-term failure of the residual heat removal system occurs while the primary side is still closed, the reactor water heats up to boiling temperature resulting in steam production in the core. The steam flows towards the SG (mainly to the SG filled with water on the secondary side) where it condenses. A special kind of reflux condensation with nitrogen present in the region above the condensation zone is established. The steam production in the core also causes the coolant inventory in the core to froth up and the swell levels rise variously in the SGs depending on how many SGs are operable at the time. Secondary sides filled with water act as main heat-sinks; hence, the frothed primary inventory is predominantly displaced to heat-removing SGs, thereby manifesting in rising swell levels in their U-tubes. This represents reflux-condenser conditions superposed by a swell level present on the U-tube inlet sides. In absence of forward coolant transport (blocked by $\mathrm{N}_{2}$ ), heat transfer may deteriorate (i.e., reactor coolant system temperature and pressure are higher) as more inventory is displaced into the heat-removing SG. In either case, pressure and temperature (i.e., $\Delta \mathrm{T}$ to secondary) in the RCS rise up to the level, where a steady-state heat flux to secondary becomes established, sufficient to transfer the whole core power to secondary side. Even in the absence of active operator interventions, a quasisteady-state condition with assured heat removal to secondary side always becomes established even if only one SG is operable. The primary equilibrium pressure required for the removal of the entire decay power depends on the heat transfer area in the U-tubes and is thus directly connected to the swell levels in the U-tubes (i.e., the equilibrium pressure depends on the distribution of the primary inventory among the number of water filled SGs). The primary inventory again is determined by the prevailing boundary conditions (e.g., number of SG in operation, additional coolant injection by active or passive systems).

In systematic parametric studies within the current test program on heat transfer in the SG U-tubes (as function of the water inventory), a range of heat transfer mechanisms and basic coherences involving the inlet-to-outlet-side transport of coolant with different effects has been identified (Figure 12), for example, as follows.

(i) State 3: intermittent spillover of boron-depleted coolant through individual short SG tubes. Following the onset of intermittent spillover, slugs of borondepleted coolant are transported over the apex of individual tubes because the condensation rate exceeds the coolant mass flow spillover. Equilibrium pressure on the RCS side is moderate and constant at 4-5 bar. This status provides potential for a continuous boron dilution process below the SG outlet tubes.

(ii) State 4: stationary slugs of subcooled water present in all SG tubes with nitrogen enclosed in the tube bends above. Tall columns of subcooled condensate reduce the heat transfer zone to the bottom part of all tubes. Degraded heat transfer capacity in the SGs leads to relatively high RCS pressure.

(iii) Sate 5: continuous circulation in some short tubes. If coolant inventory is sufficient to initiate continuous overflow in the short SG tubes, regardless of $1 \Phi$ or $2 \Phi$ flow, boron dilution resulting from the heat transfer process can be ruled out under these boundary conditions.

In order to investigate the transient behavior of events related to loss of RHRS, several integral tests applying different boundary condition were also conducted in the PKL test facility. These tests confirm the above-mentioned heat transfer mechanisms in the SG(s). However, they also demonstrate that the frame for the occurrence of the specific flow phenomena (discontinuous flow phenomenon with high steam loads) leading to boron dilution processes is very small.

In fact, in the PKL tests of series F and G, boron dilution (continuous accumulation of condensate below SG outlet(s)) as a result of coolant transport in the SGs was only observed for the scenarios with only one SG in operation (and with some additional other specific conditions). As an example Figure 13 shows in comparison the evolution of the primary pressure and the boron concentration below the SG outlet for two test runs with one and two SG in operation. Through the availability of 2 SGs and the smaller increase of primary-side inventory in the SG that results, a transfer of weakly borated water to the outlet side is avoided, and the system stabilizes at a lower pressure level.

In the international group of OECD participants in the PKL project, the so-called benchmark study with various computer programs (RELAP, CATHARE, ATHLET, TRACE, etc.) was performed for a similar scenario. The results 


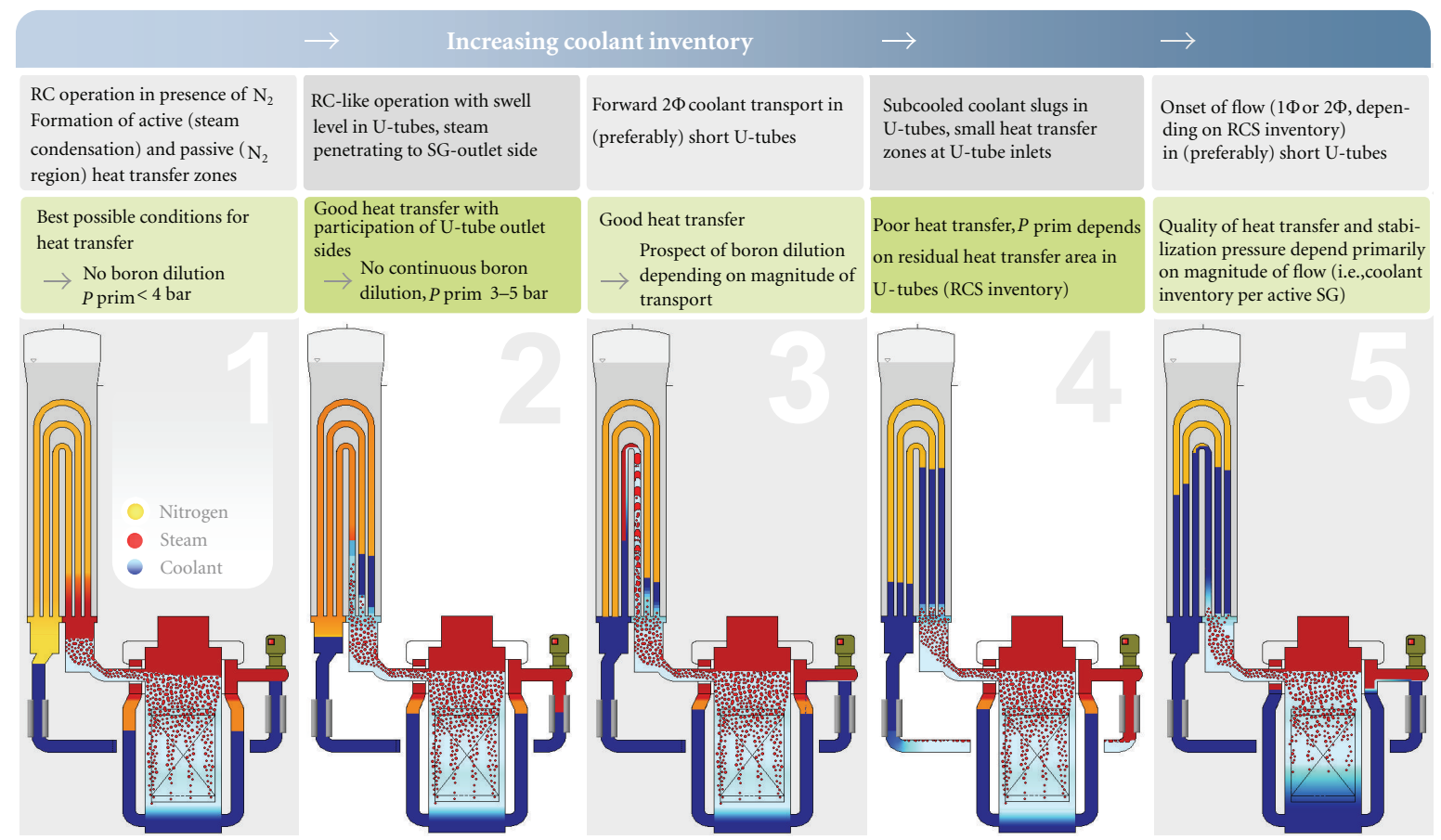

FIGURE 12: Heat transfer in the SG as function of the coolant inventory.

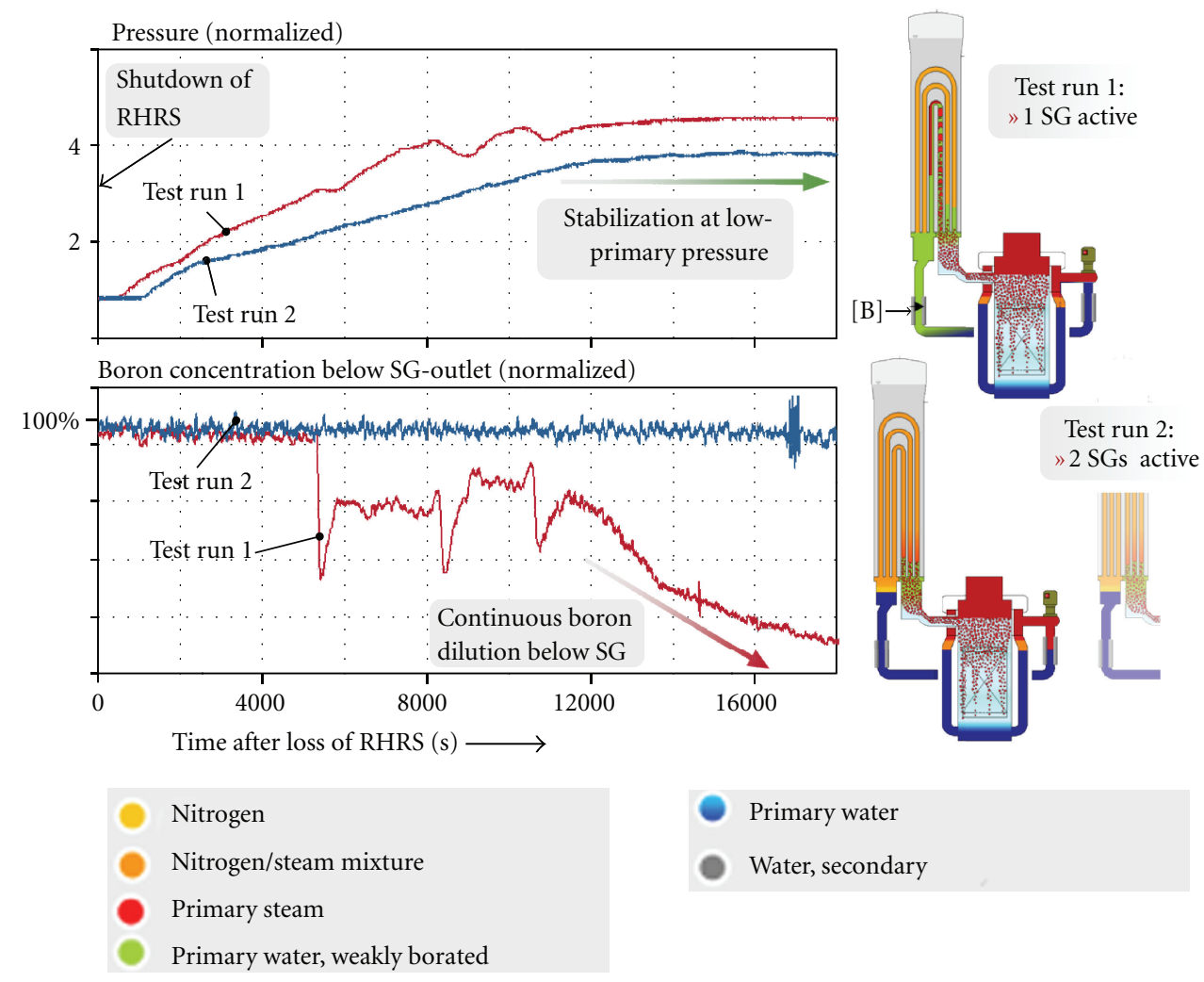

FIGURE 13: Primary pressure and boron concentrations for one and two SGs in operation. 


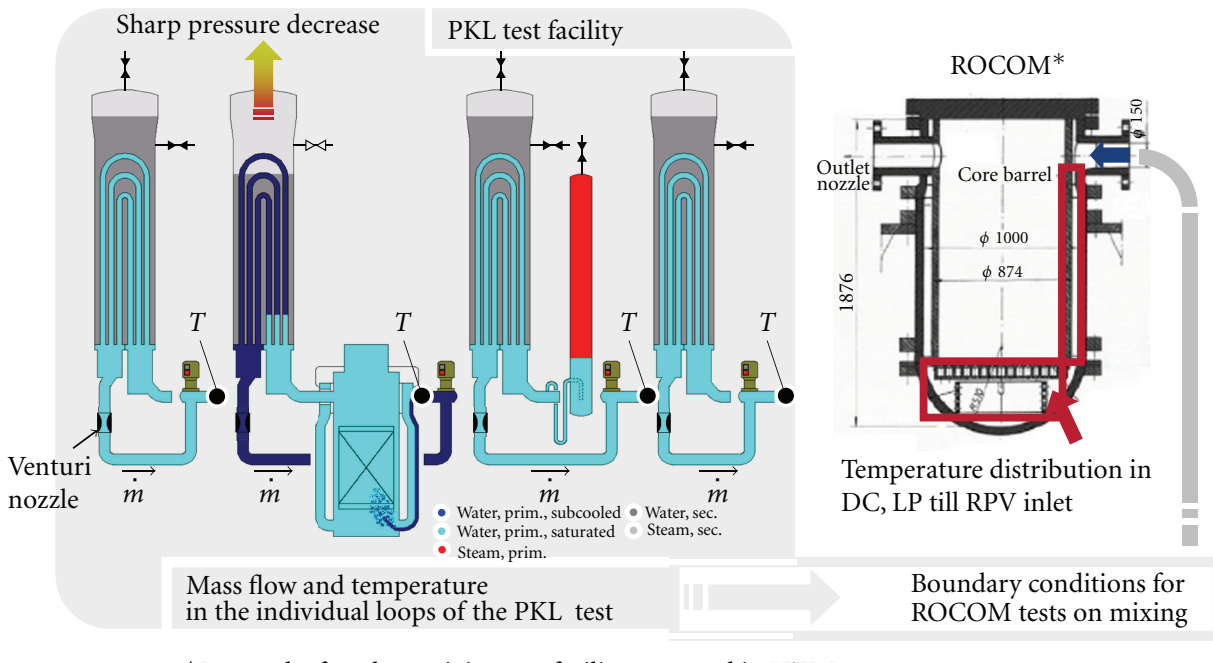

* Rossendorf coolant mixing test facility, operated in HZDR

FIgURE 14: Main steam line break in the PKL test facility.

display a large variation and make clear that to describe such complex processes, on one hand, a very detailed nodalization is required (e.g., representing the SG tubes by 3 lengths appears insufficient) and, on the other hand, it appears that the models of boron dilution are in need of improvement. Therefore, the PKL tests deliver important, detailed information for the further improvement of system codes and for the development of CFD programs that describe localized processes.

4.7. PKL Test on Main Steam Line Break. Nonisolable main steam line breaks (MSLB) cause a rapid decrease in secondary-side pressure in the affected SG. This leads to increased heat transfer from the primary to the secondary side, and therefore to pronounced cooling of the primary coolant in the affected loop (subcooling transient). An important question during this process is whether a localized recriticality of the core and the resulting power excursion can occur due to the entry of cold water into the reactor core area.

The PKL test was started from hot-standby conditions; this is because low reactor power leads to a larger decrease in coolant temperature, which represents a disadvantageous boundary condition for subcooling and recriticality. With a completely filled primary circuit, the transient was started by completely opening a valve (representing a break) in the main steam line of SG 1 and the coastdown of the reactor coolant pumps (due to the MSLB). The cross-section of the opening was chosen to represent the transient conditions of a $10 \%$ break (corresponding to the most disadvantageous break size as determined by preparatory RELAP 5 analyses of the subcooling). It is assumed that the main steam line break is located inside containment and therefore cannot be isolated. The other SGs are isolated from the break (there is no connection through the turbine bypass, MS isolation valves are closed). Due to the limiting maximum pressure of the PKL test facility, the processes that normally occur at higher pressures were represented at a reduced pressure of 45 bar. For the extrapolation to real plant conditions, additional calculations with thermal hydraulic system codes (after validation by the experiment) are necessary.

An additional, important aspect of this accident scenario concerns RPV integrity under consideration of pressurized thermal shock (PTS) due to the discharge of cold water in the RPV downcomer. This is important above all when the cooling of the primary coolant is intensified by injection of emergency cooling water into the cold leg at high primaryside pressure (up to the actuation pressure of the pressurizer safety valve (PRZ-SV)). This case is relevant for some PWR plants and was investigated in the second phase of the PKL test described here, that is, after the affected SG was completely emptied. In this process, the primary-side pressure was increased by injection from the safety-injection pumps (cold-side injection in 2 of 4 loops, Loop 1 and 4) until the PRZ-SV responded. Steam flow out of the PRZ-SV was followed later by water flow. Earlier computer calculations of this scenario indicate that, under certain boundary conditions, a reduction and partial stagnation, or even a reversal, of the natural circulation flow can occur in the primary side loops with the intact SGs.

A general goal of the test was to create a reliable database for validating computer programs. In view of the test goals (concerning PTS and recriticality), the following parameters are of decided importance:

(i) the heat transfer in the affected SG and the determination of the minimum coolant temperature at the SG outlet and at the RPV inlet,

(ii) the circulation flow in the loops with the affected and the intact SGs.

Furthermore, the results of this PKL test, which is oriented to PWR system behavior, also provide the boundary conditions for complementary tests in the ROCOM facility (Rossendorf Coolant Mixing Test Facility, operated in the research center at Dresden-Rossendorf) ([11], Figure 14) on mixing cold 


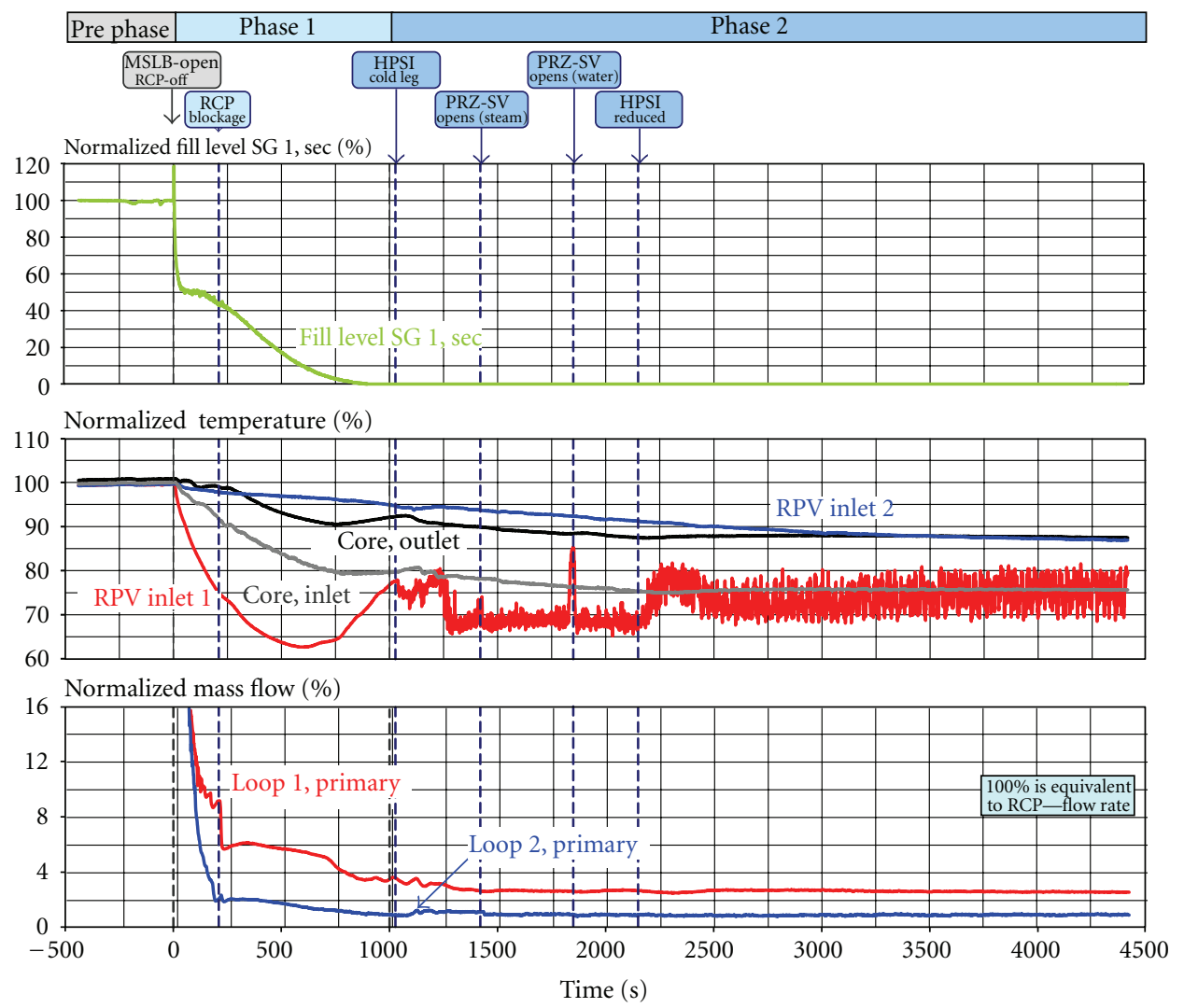

FIGURE 15: PKL test results-main steam line break.

and hot water in the RPV downcomer as well as in the lower plenum and for determining the fluid state at the core inlet.

The evolution of the main parameters of the PKL test for both phases is illustrated in Figure 15. The test results can be summarized as follows:

(i) evaporation of affected SG-inventory within approximately $1000 \mathrm{~s}$;

(ii) temperature decrease at RPV inlet in the affected loop down to approximately $60 \%$ (in relation to the initial conditions);

(iii) intense natural circulation in the affected loop, also stable natural circulation (at lower intensity) in the unaffected loops;

(iv) pronounced temperature stratification in the cold leg as a consequence of high pressure safety injection, thereby no backflow of cold water to RCPs.

The combination of the PKL and of the ROCOM experiment covers all thermal hydraulic phenomena relevant for the MSLB scenario. The test results have been intensively used for validation and optimization of analytical tools, that is, for system codes in connection with PKL and for CFD in connection with ROCOM. The discussion of pre- and posttest calculations on PKL and ROCOM performed by the project partners was one major part of an analytical workshop hosted by University of Pisa in April 2010. In addition a benchmark activity among the participating project partners on the PKL experiment including pre- and posttest calculations with all relevant system codes currently used have been also coordinated by University of Pisa [12].

The final goal now is to be able to make accurate predictions for PWRs with regard to recriticality and PTS for relevant scenarios by using the computer programs that have been validated in this way for plant calculations with PWR geometry and PWR boundary conditions.

\section{Benefits and Uses of PKL Results}

The benefits and concrete uses of the test results can be summarized under the following headings.

5.1. Validation of Computer Codes. One major benefit of the PKL experiments has been the provision of a comprehensive data base for the further development and validation of thermal-hydraulic system codes such as RELAP, CATHARE, ATHLET, MARS, and TRACE. Computer codes have to be validated before they are used for the design and licensing of reactors. One effective method of quantifying the accuracy of full-scope thermal-hydraulic codes is the predictive and confirmatory analysis of dedicated experiments in sufficiently instrumented test facilities and comparing the results with those obtained with other codes. The objective of code validation is to check the physical models and the numeric solution methods. This must be based on the existing results 
of experiments on individual phenomena and also, more particularly, on the results of integral tests. On the other hand side, the computer codes validated in this way are then used to extrapolate the experimental results to the PWR and to analyze scaling effects (geometry, pressure). Code calculations also support the performance of the tests by defining test initial and boundary conditions.

PKL test results have been widely used for validation of computer codes by the PKL project partners (e.g., [1114]). Besides the regular PKL working group meetings where results from pre- and posttest calculations are discussed, four dedicated workshops on analytical activities related to the different international PKL Projects have been held up to now (Barcelona, September 2003; Pisa, October 2005; Budapest, November 2006; Pisa, April 2010). A further joint PKL-ROSA/LSTF workshop mainly focusing on analysis related to the recently performed counterpart tests in the PKL LSTF facilities is planned for October 2012.

Based on the presentation of simulation results performed by different organizations/countries using various codes, general and common goal for all workshops is to discuss modeling issues and practices. In so far, the workshops provide an efficient way to evaluate the current code capabilities for the transients under investigation and a good opportunity to share experiences and practices among the project participants. The workshops also include plant application analysis related to equivalent scenarios.

In addition, two analytical benchmark activities among the project participants were performed up to now. The first one was related to a PKL test on loss of RHRS during midloop operation (see Section 4.6). Seven participants of six different nations using four different codes have contributed to this exercise. For the second benchmark exercise a test of the current test program dealing with cool down after a main steam line break was selected (see Section 4.7). The activity was decided into two phases, a "blind" pretest phase on the basis of initial and boundary conditions by the test design and a posttest phase after the experimental data were available. Six institutions with five thermal-hydraulic system codes were involved in the comparative exercise [12].

5.2. Application of Test Results to Topical Safety Issues. The use of knowledge gained from PKL experiments in answering issues raised by authorized experts and licensing authorities has played an important role since the initiation of the PKL project. This is by no means restricted to the previously mentioned insights gained from the experiments performed in the wake of the TMI-2 accident. Since then there have been many examples of how such insights have contributed to clarifying concerns raised by the supervisory authorities in relation to cool down or emergency procedures or on the basis of operational occurrences. For example, the sound knowledge gained from PKL experiments performed in response to queries raised by the authorized inspection agency concerning the effect of nitrogen in the event of a LOCA demonstrated that heat transport to the SGs is assured even in the event of entrainment of large quantities of nitrogen into the RCS (e.g., due to inadvertent failure to isolate accumulators). It was thus possible to assuage the safety concerns of the authorized inspection agency. Further examples of the application of test results to topical issues covered within PKL III A to D are discussed in [5].

The investigations on system behavior for small breaks with boron dilution and on shut-down plant behavior for loss of RHRS are examples for topics covered in recent years within an international cooperation. These investigations deliver the only experimental data base worldwide on PWR system behavior for boron dilution scenarios, because actual boric acid is used and detailed measurements of the local boron concentrations are made. The results contribute to the answers to current safety questions, for example, with regard to the flow velocities, size, and remaining boron concentration of condensate slugs, which must be considered under specific conditions at the RPV inlet, where the evaluation of the minimal boron concentration entering the core of a PWR is important.

\subsection{Verification/Extension of Operating Manuals and Emer-} gency Procedure Manuals. Additions to and extension of the operating manual are an ongoing process for all operators of nuclear installations which involves all insights available for improving the procedures specified in the manuals. The relevant results of PKL experiments are used in this context as are operating experiences, detailed analyses, and advances in instrumentation technology.

The generation of emergency procedures, for example, for loss of feed water supply and station blackout (secondaryand primary-side bleed and feed), is largely based on knowledge gained from relevant PKL experiments.

5.4. Operator Training. PKL test results and knowledge derived from them for PWR units are used for the training of nuclear power plant operating personnel (complementary to simulator training courses). They provide graphic illustration of thermal-hydraulic processes during accidents and operational transients. Furthermore, the test results can be used to demonstrate the effectiveness of operator actions in a practically oriented fashion. Recently, practical training courses have been held at the PKL test facility itself.

5.5. Interaction with Other Test Facilities. The PKL test results are also used to provide initial and boundary conditions for further detailed investigations in special experimental facilities, as, for example, in the ROCOM facility [11], which is operated at the Helmholtz-Zentrum Dresden-Rossendorf in Germany or the JULIETTE facility at AREVA NP in Le Creusot, France. Mention should also be made at this point of the upper plenum test facility (UPTF [5]) which was also operated by Siemens/KWU (now AREVA NP) in Germany and has now been dismantled. The results of the tests performed at the UPTF have proven to be an excellent complement for the PKL experiments. Whereas the UPTF provided a full-scale model of large parts of the reactor coolant system (RCS) for investigating the response of plant subsystems and in particular for studying individual phenomena which are highly dependent on the geometry, 
the PKL project concentrated on studying overall system response.

In order to investigate scaling effects, a number of PKL tests were also defined and carried out as counterpart to corresponding tests in other integral test facilities such as LSTF, BETHSY, and LOBI. Just recently, the test conditions for counterpart tests in the LSTF and PKL test facilities, both included in OECD Programs (ROSA 2 and PKL 2, resp.) have been intensively discussed and agreed with the international participants of both projects. The experiments dealing with SB-LOCA connected with complete failure of the high pressure safety injection pumps have been meanwhile completed in both test facilities. The results will be subject to intense scaling analyses and posttest calculations to be discussed also at the planned common analytical workshop in October 2012.

\section{Conclusions and Outlook}

For many years, extensive experimental investigations into the system response of PWRs under accident conditions have been being conducted at the PKL large-scale test facility which constitutes a full-height model of the entire RCS and major parts of the secondary side of a pressurized water reactor in the $1300 \mathrm{MW}$ class (with diameters a factor of 12 smaller). With the original studies on large- and small-break LOCAs and the modeling of transients in the following years, in particular considering beyond-design-basis conditions, the PKL experiments have covered a very broad spectrum of topics. These investigations have played a key role in German reactor safety research and certainly also contributed to the safety assessment of PWR units worldwide

Since 2001, the PKL project has been continued in the course of an international project initiated by the OECD. The major topics covered by the experiments between 2001 and 2007 were

(i) boron dilution events following SB-LOCA,

(ii) loss of residual heat removal under shut-down conditions.

The tests were conducted utilizing boric acid and boron measuring instrumentation. They provide an important contribution for the evaluation of boron dilution events and represent a unique data source for the validation of computer codes.

Additional topical safety issues, such as main steam line break or boron precipitation processes in the core following large-break LOCA, are subject to investigation in the current OECD-PKL 2 project which is scheduled to run until the end of 2011.

The tests performed to date (in total more than 150 integral experiments) have altogether contributed to a better understanding of the sometimes highly complex thermalhydraulic processes involved in various accident scenarios and to a better assessment of the countermeasures implemented for accident control. In addition, they have supplied valuable information regarding safety margins available in the plants. In particular, the test results have found concrete application in the validation and further development of thermal hydraulic computer codes, the so-called system codes.

In the light of the overriding objective of continuing to provide quick answers to topical safety concerns in the future, relevant topics of investigation for a new PKL program starting in 2012 have already been discussed with the national and international parties, such as

(i) accident situations under cold shut-down conditions with open RCS,

(ii) station blackout transients with very late initiated procedures to prevent a core melt scenario,

(iii) initiating events for severe accidents in connection with the performance of the core exit temperature.

The final program proposal will be agreed with the project partners and will consider the needs of the different countries and organizations.

\section{References}

[1] R. Mandl, B. Brand, and H. Watzinger, "PKL reflood tests including end-of-blowdown," in Proceedings of the 13th Water Reactor Safety Research Information Meeting, Gaithersburg, Md, USA, October 1985.

[2] R. M. Mandl and P. A. Weiss, "PKL tests on energy transfer mechanisms during small-break LOCAs," Nuclear Safety, vol. 23, no. 2, pp. 146-158, 1982.

[3] K. J. Umminger, W. Kastner, R. Mandl, and P. Weber, "Thermal hydraulic behavior of a PWR under beyond-designbasis accident conditions: conclusions from an experimental program in a 4-loop test facility (PKL)," in Proceedings of the 2nd ASME-JSME Nuclear Engineering Joint Conference (ICONE '93), vol. 1, pp. 409-416, San Francisco, Calif, USA, March 1993.

[4] R. Mandl and B. Brand, "PKL III small breaks and transients experimental programme," in Proceedings of the 14th Water Reactor Safety Research Information Meeting, Gaithersburg, Md, USA, October 1986.

[5] J. Liebert, B. Brand, W. Schwarz, G. Sgarz, and K. Umminger, "Results of UPTF and PKL research projects for PWR plant operation,” VGB PowerTech, vol. 79, no. 8, pp. 20-27, 1999.

[6] Y. Anoda, J. Katayama, Y. Kukita, and R. Mandl, "Secondary bleed and passive feed during PWR station blackout (TMLB’) transient: experimental simulation at full pressure and temperature," in Proceedings of the 113th ASME Annual Winter Meeting, pp. 89-96, Anaheim, Calif, USA, November 1993.

[7] B. Brand, R. Mandl, and H. Watzinger, "Investigation of PWR transients in the PKL test facility," in Proceedings of the 3rd International Topical Meeting on Nuclear Power Plant Thermohydraulics and Operations (NUPTHO '88), Seoul, Korea, November 1988.

[8] K. J. Umminger, W. Kastner, R. Mandl, and P. Weber, "Thermal hydraulic behavior of a PWR under beyond-designbasis accident conditions: conclusions from an experimental program in a 4-loop test facility (PKL)," in Proceedings of the 2nd ASME/JSME International Conference on Nuclear Engineering (ICONE '93), pp. 409-416, San Francisco, Calif, USA, March 1993. 
[9] K. Umminger, S. P. Schollenberger, S. Cornille, C. Agnoux, D. Quintin, and P. Freydier, "PKL tests on heterogeneous inherent boron dilution following Sb-Loca-applicability to reactor scale," in Proceedings of the 18th International Conference on Nuclear Engineering, Proceedings (ICONE '10), vol. 4, pp. 433439, Xi'an, China, May 2010.

[10] K. Umminger, B. Schoen, and T. Mull, "PKL experiments on loss of residual heat removal under shutdown conditions in PWRs," in Proceedings of the International Congress on Advances in Nuclear Power Plants (ICAPP '06), pp. 1776-1784, Reno, Nev, USA, June 2006.

[11] K. Umminger, L. Dennhardt, and S. Kliem, "Experiments on main steam lineBreak in the test facilities PKL and ROCOM," in Proceedings of the 14th International Topical Meeting on Nuclear Thermalhydraulics (NURETH '11), Toronto, Canada, September 2011.

[12] A. Del Nevo, E. Coscarelli, A. Kovtonyuk, and F. D’Auria, Analytical Exercise on OECD/NEA/CSNI PKL-2 Project Test G3.1: Main Steam Line Break Transient in PKL-III Facility, Pisa, Italy, 2010.

[13] F. Reventós, J. Freixa, L. Batet et al., "An analytical comparative exercise on the OECD-SETH PKL E2.2 experiment," Nuclear Engineering and Design, vol. 238, no. 4, pp. 1146-1154, 2008.

[14] A. Bucalossi, Validation of Thermal-Hydraulic Codes for Boron Dilution Transients in the Context of the OECD/SETH Project, EUROSAFE, Brussels, Belgium, 2005. 

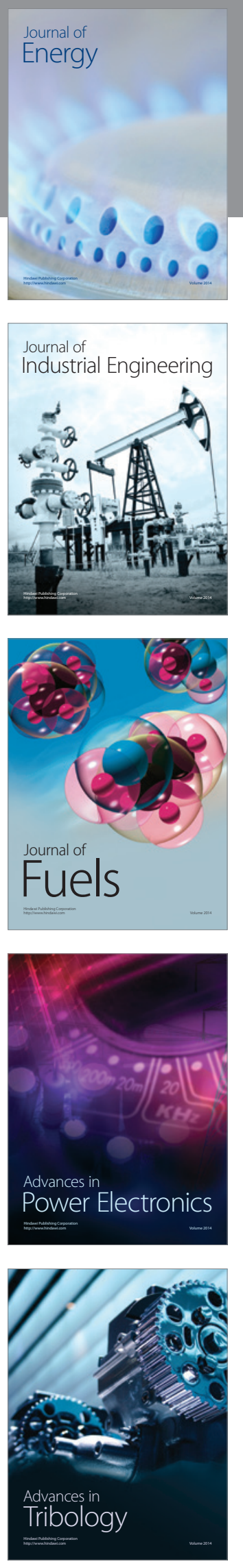
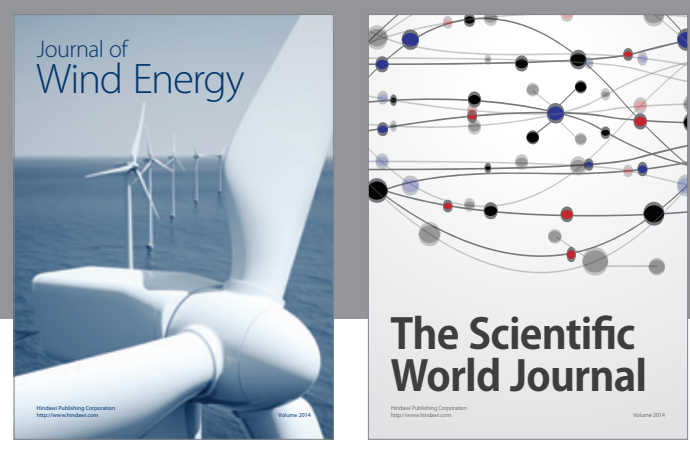

The Scientific World Journal

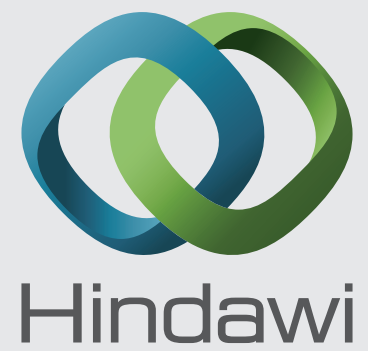

Submit your manuscripts at http://www.hindawi.com
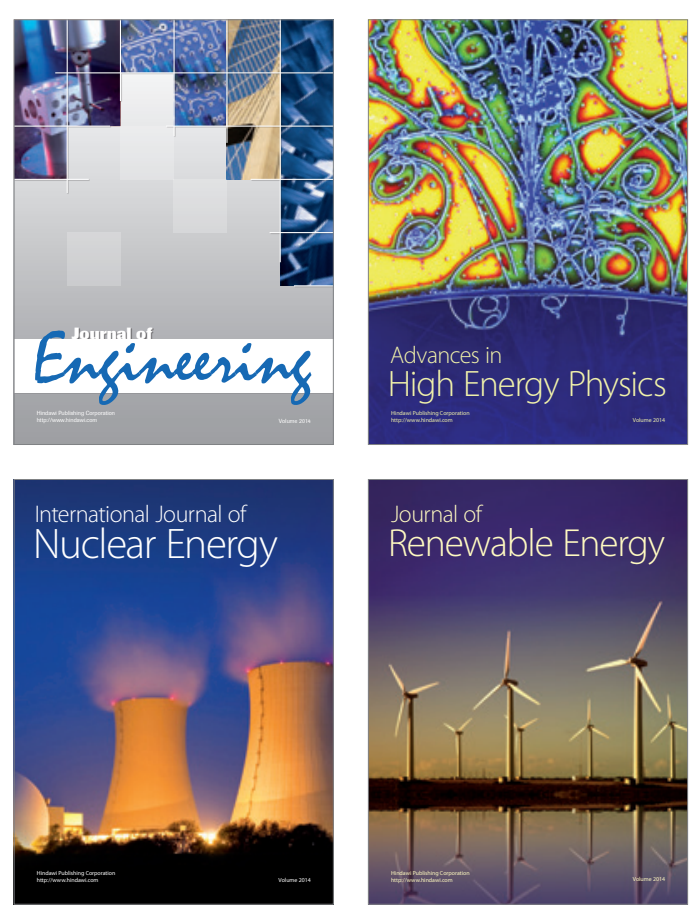

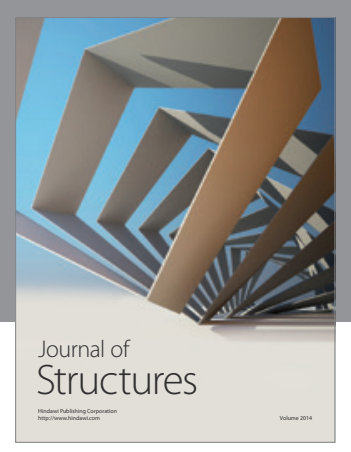

Rotating
Mechinery
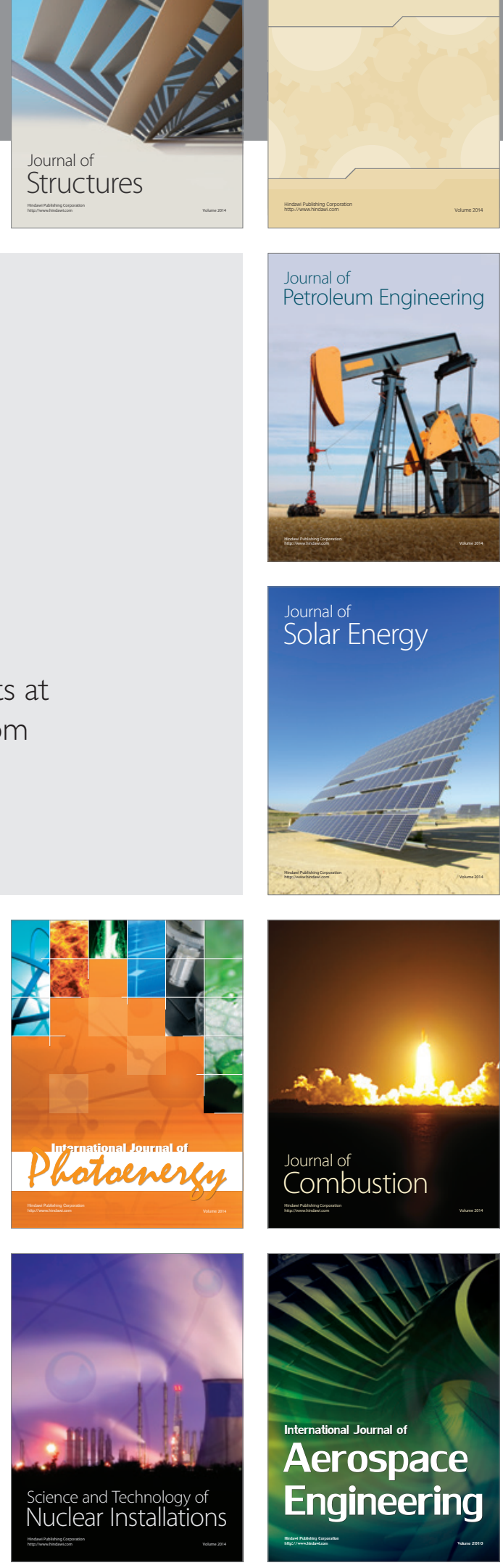